NP5 (continued)

findings into practice by supporting efforts to improve access to healthy, affordable food and places to be active. Funding: USDA Grant \#2011-68001-30103

\section{NP6 Effectiveness of Supports for Family Mealtimes on Obesity Prevention Among Head Start Preschoolers: The Simply Dinner Study}

Holly Brophy-Herb, PhD, hbrophy@msu.edu, Michigan State University, Department of Human Development and Family Studies, 552 West Circle Drive, Room 7, Human Ecology Building, East Lansing, MI 48824; M. Horodynski, RN, PhD; D. Contreras, PhD; J. Kerver, RD, PhD; M. Stein, MSW; E. McClain, MSW, Capital Area Head Start; N. Kaciroti, PhD, University of Michigan; J. Lumeng, MD, PhD

Objective: To test the main, additive and interactive effects of 6 intervention components reflecting differing levels of supports for healthy family mealtimes on reducing childhood obesity.

Description: Using the Multiphase Optimization Strategy, we are currently testing 6 intervention components in a Screening Phase in Head Start families $(\mathrm{N}=520)$, which will result in the implementation and evaluation of a "final" intervention model in the Confirming Phase $(\mathrm{N}=250)$.

Evaluation: Screening Phase analyses will test, on an intent-to-treat basis using ANOVA models, whether each intervention factor has a significant effect on frequency of healthy, family mealtimes and dietary quality pre- to post-intervention.

Conclusions and Implications: Results will inform policy (e.g. where limited resources may be best allocated) and interventions (e.g. most effective strategies for promoting mealtimes).

Funding: USDA Grant \#2015-68001-23239

\section{NP7 HomeStyles: Shaping Home} \section{Environments and Lifestyle Practices to} Prevent Childhood Obesity- A Randomized

\section{Controlled Trial}

Carol Byrd-Bredbenner, PhD, RD, FAND, bredbenner@ aesop.rutgers.edu, Rutgers University, 26 Nichol Avenue, New Brunswick, NJ 08901; J. Worobey, PhD, FAPA; J. R. Martin-Biggers, MS, RD; N. Hongu, PhD, RD; G. Hernandez, MA

Objective: To create an effective, sustainable, populationlevel obesity-prevention intervention that enables and motivates parents of preschoolers to shape their home environment and lifestyle behavioral practices to prevent excessive weight gain in their children and compare its effectiveness to control condition participants.

Description: Intervention development and implementation was guided by Social Cognitive and Adult Learning Theories, community-based participatory research, and motivational interviewing. The randomized controlled intervention trial is delivered by in-home visitors or online to English and Spanish parents of preschoolers. Focus groups with parents guided development of intervention materials. Cognitive testing with parents was used to refine intervention materials.

Evaluation: Cognitive testing of intervention materials indicated high audience acceptance and satisfaction. Training of home visitation staff delivering the intervention in-home was rated highly satisfactory by staff. Instruments for benchmarking participants and assessing intervention outcomes are valid and reliable. Preliminary time $\mathrm{x}$ treatment analyses indicate that, compared to control group parents, experimental group parents had significant improvements in family support for healthy eating, parental modeling of healthy eating behaviors, and self-efficacy for preparing healthy family meals, reducing children's intake of sugary drinks, helping children get and keep a healthy weight, and teaching children about the selling intent and poor nutritional value of foods advertised on TV. Experimental group parents also reported significantly increased overall quality of life.

Conclusions and Implications: Year 5 activities which focused on recruiting and retaining participants will be summarized. Parent cognitions and behaviors along with home environments and family lifestyle behaviors that promote healthy child growth and development have the potential to prevent excessive weight gain in preschoolers. Funding: USDA Grant \#2011-68001-30170

\section{NP8 The Use of Coupons to Motivate Healthier Snack Food Choices Among Children: Results of the CHOMPS Pilot}

Sean Cash,PhD, sean.cash@tufts.edu, Friedman School of Nutrition Science and Policy, Tufts University, 150 Harrison Avenue, Room 127, Boston, MA 02111;

A. R. McAlister, PhD, Michigan State University; C. D. Economos, PhD, Tufts University; M. E. Lehnerd, MS; W. L. Adamowicz, PhD, University of Alberta; S. R. Howell, Tufts University; E. L. Satin-Hernandez, Shape Up Somerville; A. L. Gallop, Tufts University

Objective: Prior research has shown that children's independent food purchases in convenience stores are predominantly energy-dense, nutrient-poor (EDNP) foods. Little is understood about altering this behavior to improve children's diets. This multi-disciplinary intervention applies economic, psychological, and nutritional insights to explore children's autonomous food purchase behaviors. Description: During our two-year, USDA-funded pilot, the Coupons for Healthier Options for Minors Purchasing Snacks (CHOMPS) initiative introduced kids-only coupons in convenience stores with the goal of encouraging healthier snack purchases. Set in Somerville and Medford, MA, the intervention offered coupons of varying discounts for healthier snack alternatives paired with simple health and economic marketing messages. Additionally, individual interviews (incorporating language and cognitive 


\section{NP8 (continued)}

assessments) were conducted with children from the intervention neighborhoods.

Evaluation: Here, we report on the observed purchase patterns of children and their responses to the coupon intervention in participating stores, as well as follow-up assessments with individual children. Across more than 2,900 separate purchase events we noted only modest coupon usage in the intervention phase. However, chip and candy purchases decreased significantly, and the percentage of purchase events that included at least one targeted healthier food item tripled.

Conclusions and Implications: Initial results indicate that kids-only coupons can play a role in shifting snacking behavior outside of school settings. We anticipate that additional results from more active promotion of the coupons (i.e. combining the discounts with other promotional materials) will be of even greater magnitude.

Funding: USDA Grant \#2014-69001-21756

\section{NP9 Fighting Obesity Among Low-Income 9-14 Year Olds: A Home-Based Intervention Using Mobile Phones to Deliver Customized Nutrition Outreach}

Peter Clarke,PhD, chmc@usc.edu, University of Southern California, Annenberg School for Communication and Journalism, ASC 324G, Los Angeles, CA 90089;

S. Evans, $P h D$

Objective: To fight obesity and poor nutrition among 914 year olds in families who patronize food pantries.

Description: We have developed a mobile phone application with customized recipes and practical, evidencebased ideas about healthy eating, keyed to each household's needs. Formative studies and usability trials have shaped the app.

Evaluation: A randomized field trial is nearly completed. Early results show that mothers (who are household cooks) and their 9-14-year-old children use the app intensively, across a month-long study period. Experimental cooks who were provided the app are three times more likely to use fresh vegetables in meals and snacks than control cooks who were provided the same vegetables by their pantries, but lack the app.

Conclusions and Implications: Further data analysis is underway.

Funding: USDA Grant \#2012-68001-19592

NP10 Developing the Mentoring, Education, and Nutrition Knowledge for Teachers to Reduce Obesity Risk in Children (M.E.N.T.O.R.) Project: In-Service and Pre-Service Teacher Needs Assessment Results

Catherine Coccia,PhD, RD, ccoccia@fiu.edu, Florida International University, 11200 SW 8th Street, AHC5 316, Miami, FL 33199; K. Brogan-Hartlieb, PhD, RD;

G. Senokossoff, PhD, Coker College; A. Campa, PhD, RD, Florida International University; F. Huffman, $P h D, R D$
Objective: To assess in-service (SCTs) and pre-service (PCTs) teachers' knowledge, beliefs and self-efficacy for creating an anti-obesogenic school environment. The secondary aim was to determine the perceived usefulness of programmatic materials.

Description: This is a cross-sectional study of 85 PCTs (92.9\% female) recruited from upper-level elementary education reading courses and 24 SCTs ( $80 \%$ female; Mean $(\mathrm{SD})=13.58(9.35)$ years experience teaching) from a Title 1 public elementary school in the southeast region of the United States. Participants completed a self-report questionnaire measuring demographics, nutrition knowledge, beliefs about the school food environment, and self-efficacy for teaching nutrition. Descriptive statistics for each study variable were calculated by SPSS v.22.0.

Evaluation: SCTs and PCTs reported low levels of nutrition knowledge with an average of $66 \% \pm 14.69$ and $70 \% \pm 12.79$ respectively. Consequently, only $30.4 \%$ of SCTs and $29.1 \%$ of PCTs indicated that they have the skills necessary to teach nutrition concepts effectively. Seventyfive percent of SCTs and $96.5 \%$ of PCTs reported it is important to have a healthy school environment. Lack of training in nutrition was a major issue with SCTs (93.9\%) indicating in-service training and reference materials on nutrition education were not available. Despite this, $77 \%$ indicated that these resources had moderate or great potential to improve nutrition education. SCTs and PCTs both reported that audio and visual aids along with laboratory materials and computer software would be useful materials for nutrition education.

Conclusions and Implications: Results from this study suggest a need for nutrition education among SCTs and PCTs and will guide the development of a nutrition education program that leverages PCTs as agents of change to improve children's nutrition behaviors.

Funding: USDA Grant \#2015-690011-23241.

\section{NP11 Best Practices and Lessons Learned From the Choose to Change Project: Nutrition Education and Interventions for Preschool Children}

Lesley Cottrell,PhD, 1cottrell@hsc.wvu.edu, West Virginia University, One Medical Drive, PO Box 9214, RCBHSC, Morgantown, WV 26506-9214; K. Viggiano, MPH; E. Murphy, PhD; E. Bowen, PhD; D. Lacombe, PhD; S. Wilkinson, BA; T. Harris, PhD; J. Strager, PhD; M. Strager, PhD

Objective: The Choose to Change (C2C) project incorporates preschool and family-based intervention components designed to improve knowledge and attitudes about daily practices that contribute to unhealthy eating and sedentary behavior in early childhood. The goal of the project is to positively impact preschool children's dietary habits and physical activity patterns while in preschool and to sustain healthy behaviors through teacher and parent reinforcement and modeling. 